\title{
Novel Roles for Chloride Channels, Exchangers, and Regulators in Chronic Inflammatory Airway Diseases
}

\author{
Monica Sala-Rabanal, ${ }^{1,2}$ Zeynep Yurtsever, ${ }^{2,3,4,5}$ Kayla N. Berry, ${ }^{4,6}$ and Tom J. Brett ${ }^{1,2,4,5,7}$ \\ ${ }^{1}$ Department of Cell Biology and Physiology, Washington University School of Medicine, St. Louis, MO 63110, USA \\ ${ }^{2}$ Center for the Investigation of Membrane Excitability Diseases, Washington University School of Medicine, St. Louis, MO 63110, USA \\ ${ }^{3}$ Biochemistry Program, Washington University School of Medicine, St. Louis, MO 63110, USA \\ ${ }^{4}$ Department of Internal Medicine, Washington University School of Medicine, St. Louis, MO 63110, USA \\ ${ }^{5}$ Drug Discovery Program in Pulmonary and Critical Care Medicine, Washington University School of Medicine, St. Louis, \\ MO 63110, USA \\ ${ }^{6}$ Medical Scientist Training Program, Washington University School of Medicine, St. Louis, MO 63110, USA \\ ${ }^{7}$ Department of Biochemistry and Molecular Biophysics, Washington University School of Medicine, St. Louis, MO 63110, USA
}

Correspondence should be addressed to Tom J. Brett; tbrett@wustl.edu

Received 24 August 2015; Accepted 13 October 2015

Academic Editor: Mauricio Retamal

Copyright (C) 2015 Monica Sala-Rabanal et al. This is an open access article distributed under the Creative Commons Attribution License, which permits unrestricted use, distribution, and reproduction in any medium, provided the original work is properly cited.

Chloride transport proteins play critical roles in inflammatory airway diseases, contributing to the detrimental aspects of mucus overproduction, mucus secretion, and airway constriction. However, they also play crucial roles in contributing to the innate immune properties of mucus and mucociliary clearance. In this review, we focus on the emerging novel roles for a chloride channel regulator (CLCA1), a calcium-activated chloride channel (TMEM16A), and two chloride exchangers (SLC26A4/pendrin and SLC26A9) in chronic inflammatory airway diseases.

\section{Introduction}

The chronic inflammatory airway disease, asthma, and chronic obstructive pulmonary disease (COPD) are significant causes of morbidity and mortality in children and adults. Asthma affects over 300 million people worldwide, and the prevalence is increasing among all demographics. COPD is currently the third leading cause of death in USA. These diseases are hallmarked by a Th2-mediated inflammatory response which drives the three pathologies that contribute to airway obstruction in these diseases: chronic inflammation; airway muscle constriction due to airway hyperreactivity (AHR); and mucus overproduction due to mucous cell metaplasia $(\mathrm{MCM})$. A central feature of these diseases is production of the inflammatory cytokines IL-4 and IL-13, which drive MCM and contribute to AHR.

The inflammatory signaling upregulates the expression of hundreds of proteins in the airway epithelia. A number of these proteins have roles in anion transport across membranes, including chloride channels, channel regulators, and transporters. The identity, function, and elucidated mechanism of action of these proteins have lagged behind their cation channel counterparts. However, recent advances in several technologies, including high throughput screening, have made it possible to consider the development of specific inhibitors and activators for these classes of proteins [1]. The development of such therapeutics, however, requires an intimate knowledge of the roles these proteins play in airway homeostasis and mucociliary clearance. Anion channels play very crucial roles in mucus function. Mucus is composed of $97 \%$ water and $3 \%$ solids, with the main solid component being the mucin proteins [2]. Mucin proteins are secreted in a dehydrated form and require anion channel activity to instill chloride and bicarbonate ions that ensure proper salination, hydration, and $\mathrm{pH}$ of the mucus gel layer. Proper control of this is crucial as is exemplified by the disease cystic fibrosis 
(CF), which is caused by loss of function mutations to the chloride channel cystic fibrosis transmembrane conductance regulator (CFTR) that produces thick, sticky mucus deficient in mucociliary clearance or innate antimicrobial properties [3].

Here we discuss what is currently known about the function of four exciting, new, and emerging proteins affecting anion channel activity in inflammatory airway epithelia: a chloride channel regulator (CLCA1), a calcium-activated chloride channel (TMEM16A), and two chloride exchangers (SLC26A4/pendrin and SLC26A9). In particular, we focus on recently uncovered contributions to airway diseases and mucus function, in order to answer whether they can be targeted by inhibitors or activators and whether they should be.

\section{The CLCA Family of Chloride Channel Regulators}

The CLCA family of proteins was originally misidentified as calcium-activated chloride channels and has long been associated with chronic inflammatory airway diseases. Their evolving functional identity and the possible role they play in these diseases have only recently been elucidated.

2.1. CLCAs: Association with Chronic Inflammatory Airway Diseases. Asthmatic inflammation results from a Th2mediated mechanism, where the cytokines IL- 4 and IL-13 bind their receptors and activate the transcription factor STAT6 to drive inflammation and mucus overproduction in the airways $[4,5]$. In mouse models of both allergic and respiratory virus induced-asthma, CLCA1 (previously known as mCLCA3 or gob-5) expression has been solidly linked to IL-13 driven MCM $[6,7]$ and controversially linked to AHR [6], both hallmarks of asthma and COPD. Similar results were observed in vitro with the human pulmonary mucoepidermoid cell line NCI-H292, in which expression of the protein significantly increased mucin gene MUC5AC expression and subsequent mucus production $[8,9]$, implying that CLCA1 can drive MCM. Studies using $\mathrm{Clcal}^{-/-}$mice, however, have failed to show reduced response to IL-13 stimulation, as these mice showed the same phenotype as wild-type (WT) mice $[7,10]$. Other members of the family, particularly CLCA2 and potentially CLCA4A and CLCA4B, have also been observed to be upregulated and to induce and colocalize with the inflammatory mucin protein, MUC5AC [7]. These results indicate a possible functional redundancy between members of the mouse CLCA family, which is unlikely to translate to human biology, as there are only three human CLCA proteins, compared to the seven mouse CLCA proteins [11] (Figure 1).

Of the three human CLCA proteins, CLCA1 has been identified as a potential biomarker of inflammation and MCM in the airways [12] and suggested as a potential drug target for treatment of asthma and COPD. Similar to mouse CLCA1, overexpression of human CLCA1 in NCI-H292 cells increases MUC5AC expression and mucus levels $[6,8,9]$. Its expression is upregulated in primary cell models of IL13 driven MCM and siRNA-mediated knockdown of CLCA1 prevents IL-13-driven mucus overproduction [9]. These experimental observations suggest a central role for CLCA1 function in IL-13-mediated MCM (Figure 2). Additionally, it is highly overexpressed in the airway epithelia of asthmatic patients [8] and can be found in the bronchoalveolar lavage fluid (BALF) at high levels [13]. In contrast, other members of the human CLCA family are not upregulated in response to IL-13 $[8,9]$, suggesting that CLCA1 is the sole family member with an essential role in MCM in human airways.

\subsection{The Conceptual Evolution of CLCA Proteins from "Chan-} nels" into "Channel Regulators". The family of CLCA proteins were first cloned from bovine and murine samples, where overexpression of these proteins increased $\mathrm{Ca}^{2+}$-sensitive $\mathrm{Cl}^{-}$ conductance, which led to their initial misannotation as $\mathrm{Ca}^{2+}$-activated $\mathrm{Cl}^{-}$channels (CaCCs) [14-16]. In addition, observations that nonspecific chloride channel blockers, such as niflumic acid and DIDS, seemed to reduce both currents and the mucus production [17] erroneously supported this hypothesis. However, modern bioinformatics algorithms and experimental approaches have definitively demonstrated that CLCA proteins are soluble, secreted proteins that do not constitute ion channels themselves $[13,18]$, and subsequent studies demonstrated that CLCA proteins activate currents through an endogenous $\mathrm{CaCC}$ [18-20]. As a consequence, the CLCA nomenclature has been updated and the family is now recognized as $\mathrm{Ca}^{2+}$-activated $\mathrm{Cl}^{-}$channel regulator proteins. All members of this family (with the exception of the likely pseudogenes human CLCA3 and mouse CLCA4C) are synthesized as full-length proteins and proteolytically cleaved into two fragments. It has been demonstrated that, for some of the family members, the cleavage is carried out by a zincdependent matrix metalloprotease-like (MMP-like) domain located in the $\mathrm{N}$-terminus of the protein $[18,21]$ (Figure 1). However, sequence analysis has revealed that all CLCA family members contain the required MMP active site motif [18]; thus self-cleavage is likely a conserved feature of all CLCAs. Self-cleavage is required to unmask the $\mathrm{N}$-terminal fragment of CLCA1, which then interacts with the CaCC [18] (Figure 2). The molecular identity of this previously unknown CaCC has been shown to be TMEM16A and the direct interaction between the channel and the $\mathrm{N}$-terminal fragment stabilizes and increases the cell surface expression of the channel, thereby increasing currents [20].

\subsection{CLCA1 as a Potential Regulator of Cytokine Expression.} Upstream of CLCA1 expression, the involvement of Th2cytokines IL- 4 and IL-13 has been shown in cellular and animal models as discussed above. The relationship between CLCA1 and downstream cytokine signaling, however, is still under investigation. The few articles that do exist report contradictory observations regarding the role of CLCA1 as a signaling molecule for cytokine expression. Challenging $\mathrm{Clcal}^{-/-}$mice with lipopolysaccharide (LPS), Long et al. observed increased KC (keratinocyte-chemoattractant) levels in BALF, but no change in MIP-2 (macrophage inflammatory protein 2) or IL-17 levels in the knockout mice compared 


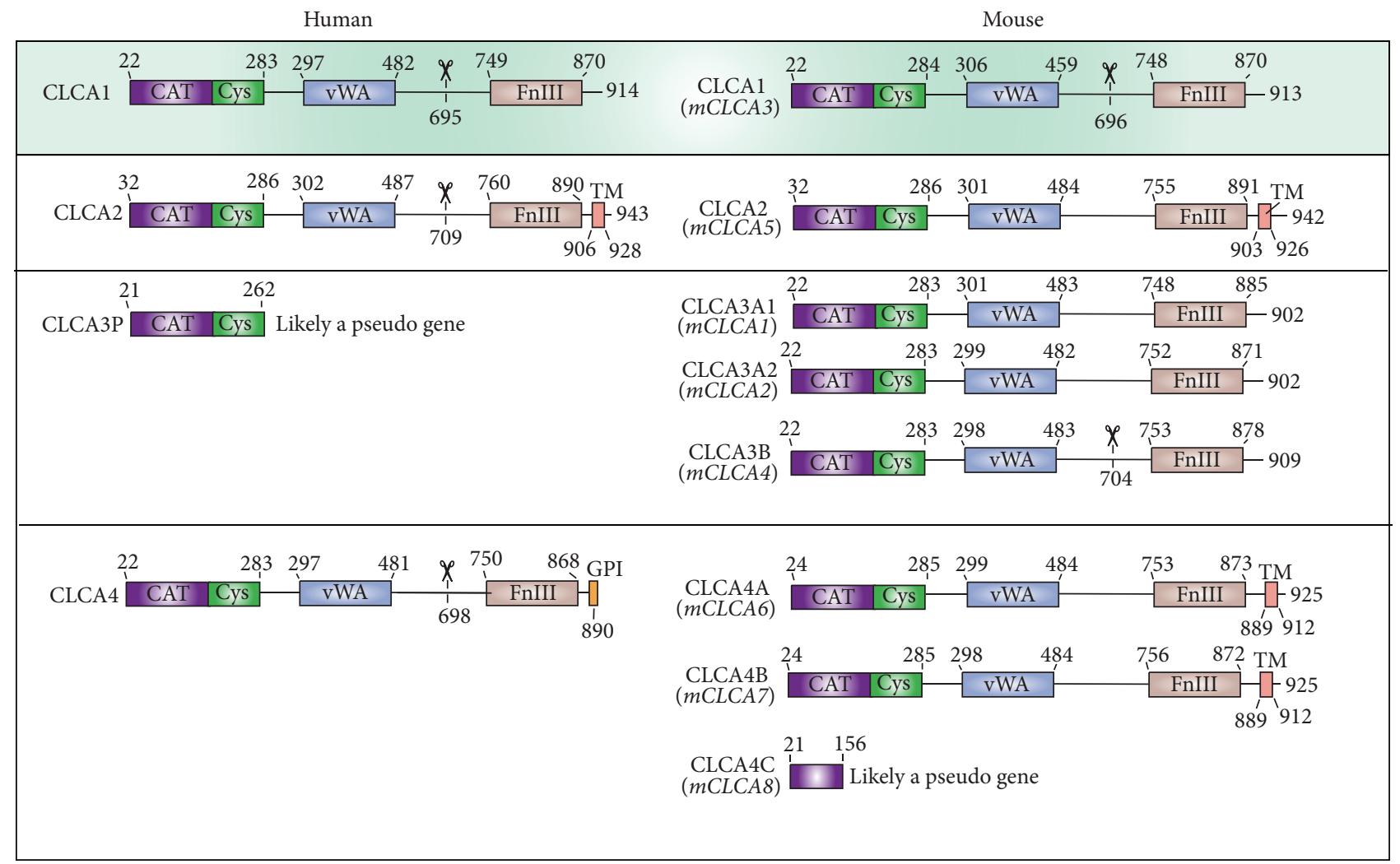

FIgURE 1: Domain architecture schematic for human and mouse CLCA proteins. Each row contains the corresponding human and mouse homologs. Mouse CLCA proteins are labeled according to the recently updated naming commissioned by the Mouse Gene Nomenclature Committee (MGNC) in order to align the numbering established by the Human Gene Nomenclature Committee and the Rat Genome Database. The previously used names for the mouse proteins are shown below the current names and are in italics. Scissors denote the experimentally determined location of proteolytic cleavage sites [18]. Human CLCA3 and mouse CLCA4C are likely pseudogenes because they contain premature stop codons. Labels denote the following domains: CAT: matrix-metalloprotease-like catalytic domain; CYS: matrix-metalloprotease-like cysteine rich domain; vWA: von Willebrand factor type A domain; FnIII: fibronectin type III domain; TM: transmembrane domain; GPI: glycosylphosphatidylinositol anchor.

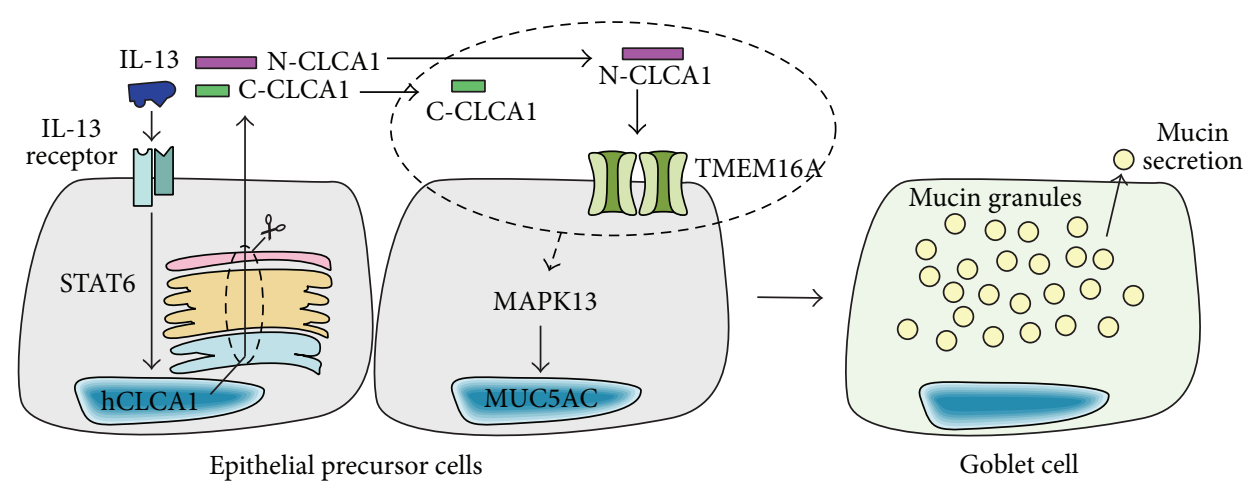

FIGURE 2: Schematic of CLCA1-driven MCM in human airways based on the current literature. IL-13 induces CLCA1 gene expression through activated STAT6. CLCA1 protein is expressed, is secreted, and undergoes proteolytic self-cleavage to yield two fragments (N-CLCA1: $\mathrm{N}$-terminal fragment; C-CLCA1: C-terminal fragment). N-CLCA1 engages and activates the CaCC TMEM16A. Downstream, a signaling pathway is activated through MAPK13 which leads to induction of the inflammatory mucin MUC5AC, followed by goblet cell differentiation and subsequent MCM. It is currently unknown whether or how the steps highlighted in the dashed ellipse (CLCA1 cleavage and activation of TMEM16A) contribute to the activation of MAPK13. 


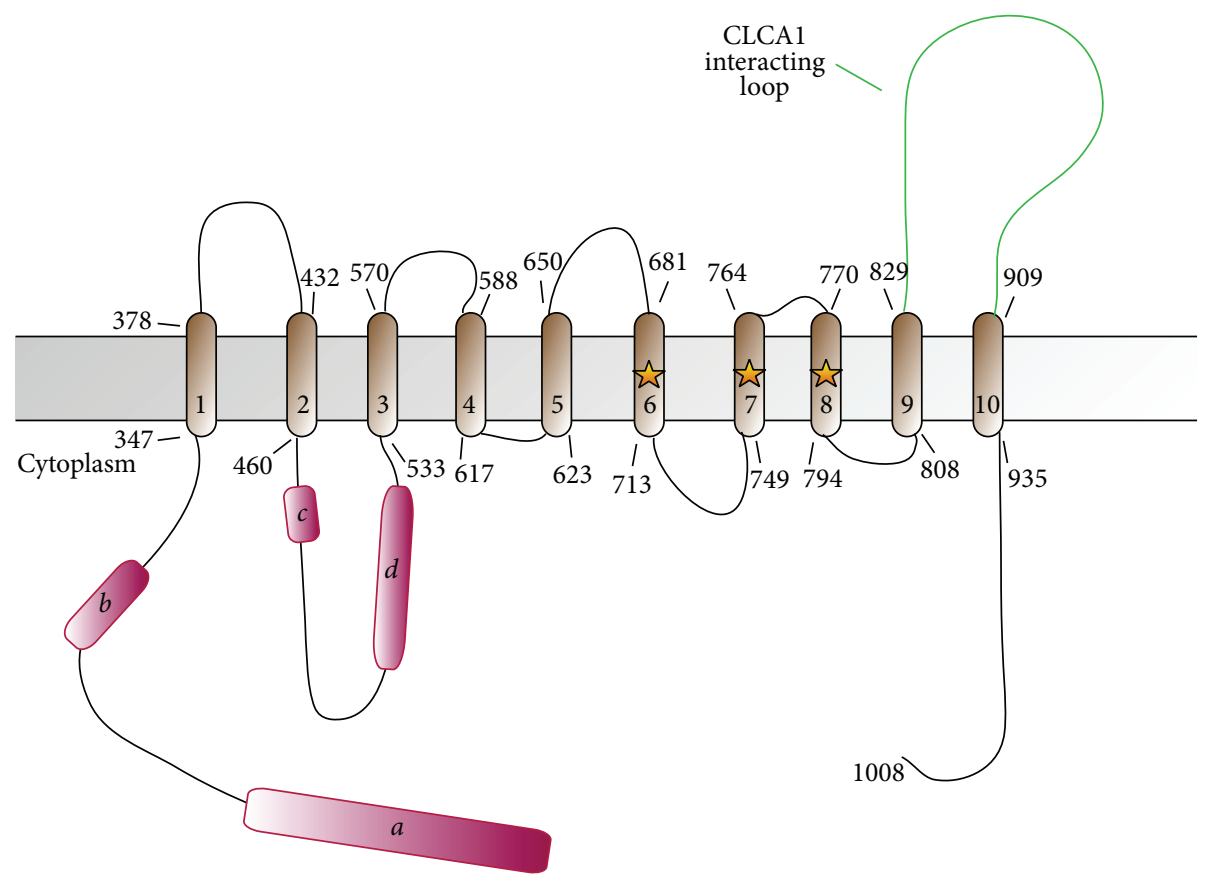

FIGURE 3: Domain architecture schematic for human TMEM16A. Topology shown is predicted from structure-based alignment to the crystal structure of the fungal Nectria haematococca TMEM16 [31]. Alternative splicing segments $a, b, c$, and $d$ are shown in magenta. The location of residues of a crystallographically determined $\mathrm{Ca}^{2+}$ binding site is highlighted with stars. The extracellular loop mediating interaction with CLCA1 is highlighted in green.

to WT mice [22]. In contrast, Dietert et al. observed significantly decreased levels of IL-17 and CXCL-1 in BALF from the $\mathrm{Clcal}^{-/-}$mice infected with Staphylococcus aureus [23]. Using a cellular model of inflammation, Ching et al. showed that CLCA1-conditioned media increased proinflammatory cytokine (IL-6, IL-8, IL-1 $\beta$, and TNF $\alpha$ ) mRNA levels in monocyte cell line U-937 and primary porcine alveolar macrophages. Immunopurified CLCA1 protein only increased IL- 8 and IL-1 $\beta$ levels significantly [24]. If such a regulatory mechanism exists for cytokine expression, modulation of CLCA1 function with small molecules to treat mucus cell metaplasia might also alter the inflammatory response in the airways.

\section{TMEM16: The First Family of CaCCs}

While CaCC conductance was a long-observed phenomenon in the airways and could be separated from CFTR currents, the molecular identity of the channels responsible for these currents remained elusive until the late 2000s. The TMEM16/Anoctamin family was identified in 2008 as the first bona fide CaCCs [25-27]. However, based on their electrical and pharmacological characterization, only two of the ten family members, TMEM16A and TMEM16B, displayed properties previously observed for CaCCs in the airways [28,29], whereas most of the other members function as lipid scramblases. Of these two, TMEM16A expression has been verified in airway epithelium and airway smooth muscle cells [30].
3.1. TMEM16A Is Linked to Chronic Inflammatory Airway Diseases. The predicted topology for TMEM16 family members is based on the recent landmark crystal structure of the fungal Nectria haematococca TMEM16 (nhTMEM16) which has 10 transmembrane domains instead of the previously predicted 8 (Figure 3) [31]. The purified and reconstituted protein, which was shown to be a homodimer [32], constitutes a channel on its own and does not require other proteins to be active [33]. While the $\mathrm{Ca}^{2+}$ sensitivity of the channel is well documented $[31,34,35]$ and the protein directly binds $\mathrm{Ca}^{2+}$, the possible involvement and mechanism of interaction with calmodulin as a calcium sensor and binding partner are still controversial [35-37].

Much like CLCA1, expression of TMEM16A is upregulated by IL-4/IL-13 stimulation [38-41]. Upon upregulation, TMEM16A colocalizes to the apical plasma membrane of goblet cells along with the mucin MUC5AC [41-43]. It is expressed in airway smooth muscle cells and has been shown to play a role in AHR [42]. Additionally, inhibitors of TMEM16A have been shown to block mucus secretion $[42,44]$ whereas small molecule activators increase secretion [45].

3.2. The Potential for Targeting CLCA1 and TMEM16A in Chronic Inflammatory Airway Diseases. CLCA1 is a promising therapeutic target for asthma and COPD, as it is the only member of its family to be upregulated in models of IL-13 mediated mucus overproduction [9], is a secreted protein [18], is expressed in goblet cells $[7,9,16]$, and associates with mucin granules $[46,47]$. Overexpression of CLCA1 in airway 
epithelium induces MUC5AC expression via a signaling cascade involving the kinase MAPK13, and siRNA-knockdown of CLCA1 blocks mucus production in these models [9], implying a critical role for CLCA1 function in inflammatory mucus production. Consistent with these observations, DNA vaccines [48] and antibodies targeting mouse CLCA1 [49] have displayed some effectiveness in reducing airway inflammation and MUC5AC levels in mouse asthma models. Similarly, as mentioned above, TMEM16A inhibitors block ATP-dependent mucus secretion, suggesting a central role for this pair in inflammatory mucus overproduction. However, it should be noted that these small molecules have relatively low potency and questionable selectivity and these findings need to be supported by additional experiments to determine the role TMEM16A plays in mucus secretion [50]. An important question that currently remains unanswered is what role this pair of molecules plays in mucociliary clearance. It is well known that anion channel activity is required for secreted mucins (MUC5AC and MUC5B) to function properly in a mucosal immunity and mucociliary clearance capacity [51]. Mucin proteins are secreted in dense, dehydrated granules and require anion channel passage of chloride and bicarbonate ions to ensure proper hydration, salination, and $\mathrm{pH}$ control [2]. Thus, any therapy targeting anion channel activity in airway diseases should proceed with caution to avoid any potential detrimental impacts to mucociliary clearance and innate mucosal immunological properties. Along these lines, exploiting the mechanism CLCA1-mediated regulation of TMEM16A action might be a possible therapeutic route for CF, utilizing a potential compensatory channel to make up for loss of CFTR activity [52]. Further along these lines, TMEM16A has been shown to carry not only chloride ions but also bicarbonate ions [36]; thus activation of TMEM16A in the setting of CF could be beneficial to adjust mucus hydration and $\mathrm{pH}$.

\section{SLC26: An Ancient Family with Unexpected New Roles}

Over the last decade the anion exchanger pendrin (PDS, SLC26A4), once thought to be limited mainly to the inner ear, kidney, and thyroid, has been found to be upregulated by inflammatory cytokines in the bronchial epithelium, where it contributes to the pathogenesis of inflammatory airway diseases [53-55] and also to the host response to bacterial infections $[56,57]$. Another member of the family, SLC26A9, is prominently expressed in the airway epithelia, where it interacts with CFTR to modulate mucus production [58]. The discovery of these crucial roles in lung physiology and pathophysiology makes these anion transporters intriguing new biomarkers for airway disease and promising novel pharmacological targets.

4.1. Pendrin: An Anion Exchanger with Critical Roles in Ear, Kidney, and Lung Physiology. Pendrin (PDS, SLC26A4) is a member of the SLC26 family of multifunctional anion transporters and channels $[59,60]$. The eleven mammalian SLC26 genes encode proteins with cytoplasmic N-termini and C-termini flanking a transmembrane core of unknown structure, predicted to span the lipid bilayer 10 to 14 times (Figure 4). Mutagenesis, homology modeling, and molecular dynamics simulation data are consistent with the hypothesis that the SLC26 transmembrane fold consists of two nesting, inverted repeats of 5-7 helices, resembling that of the CLC $\mathrm{Cl}^{-} / \mathrm{H}^{+}$antiporter channel proteins $[61,62]$ and the recently solved three-dimensional structure of SLC26Dg, a bacterial $\mathrm{H}^{+}$-coupled fumarate symporter, has clarified this [63]. It has been suggested that SLC26 proteins organize in functional homodimers or homotetramers [64], though each subunit is thought to constitute an independent translocation pathway. The C-terminal cytoplasmic region of all SLC26 proteins includes a sulfate transporter and antisigma factor antagonist (STAS) domain (Figure 4), which has been implicated in nucleotide binding and hydrolysis [65]. SLC26A4, or pendrin, functions as an electroneutral exchanger of $\mathrm{Cl}^{-}, \mathrm{HCO}_{3}{ }^{-}$, $\mathrm{I}^{-}, \mathrm{NO}_{3}{ }^{-}$, formate, $\mathrm{SCN}^{-}$, and other monovalent anions. It is expressed in cochlear epithelial cells of the spiral prominence, in root cells, in spindle cells of the stria vascularis, in epithelial cells of the endolymphatic sac, and in epithelial cells surrounding the hair cells of the saccule, utricle, and ampulla [66]. Additionally, pendrin is expressed in the apical membrane of thyrocytes $[67,68]$, renal collecting duct Type $B$ intercalated cells [69], salivary gland cells [70], and airway epithelia [53].

Pendrin function is important in several settings. In the inner ear, pendrin helps maintain $\mathrm{Cl}^{-}$and $\mathrm{HCO}_{3}{ }^{-}$homeostasis, which is crucial for normal hearing and for the development of bony structures such as the cochlea and the vestibular aqueduct [71]. In the thyroid gland, pendrin contributes $\mathrm{I}^{-}$ to the follicle for thyroxine biosynthesis [72], and in the cortical collecting duct the transporter is implicated in $\mathrm{Cl}^{-}$ reabsorption through functional coupling with the epithelial $\mathrm{Na}^{+}$channel ENaC and the $\mathrm{Na}^{+}$-dependent $\mathrm{Cl}^{-} / \mathrm{HCO}_{3}{ }^{-}$ exchanger NDCBE/SLC4A8 [73]. Most interestingly, it has been shown that in the bronchial epithelium pendrin mediates an increase in $\mathrm{Cl}^{-} / \mathrm{SCN}^{-}$exchange in response to IL-4 stimulation [74] to provide $\mathrm{SCN}^{-}$substrate to lactoperoxidase for the synthesis of hypothiocyanite $\left(\mathrm{OSCN}^{-}\right)$, a molecule with antimicrobial properties [75], and this underscores the emerging role of pendrin in innate airway defense mechanisms (Figure 5).

4.2. Pendrin and the Pathogenesis of Inflammatory Lung Disease: Too Much of a Good Thing? Pendrin was first identified by positional cloning as the disease gene for Pendred syndrome (OMIM number 247600), an autosomal recessive condition characterized by deafness with enlargement of the vestibular aqueduct, complex abnormalities in cochlear structure, and variably penetrant euthyroid goiter [76-78]. Pendrin is also implicated in DFNB4, an autosomal recessive form of nonsyndromic deafness [79]. SLC26A4 mutations that are clinically associated with Pendred syndrome cause complete loss of transport function when studied in heterologous expression systems, mostly due to retention in various intracellular compartments, whereas those exclusively associated with DFNB4 have residual transport activity [80]. In recent years, pendrin gain of function, mainly due to increased surface expression, has been linked to respiratory 

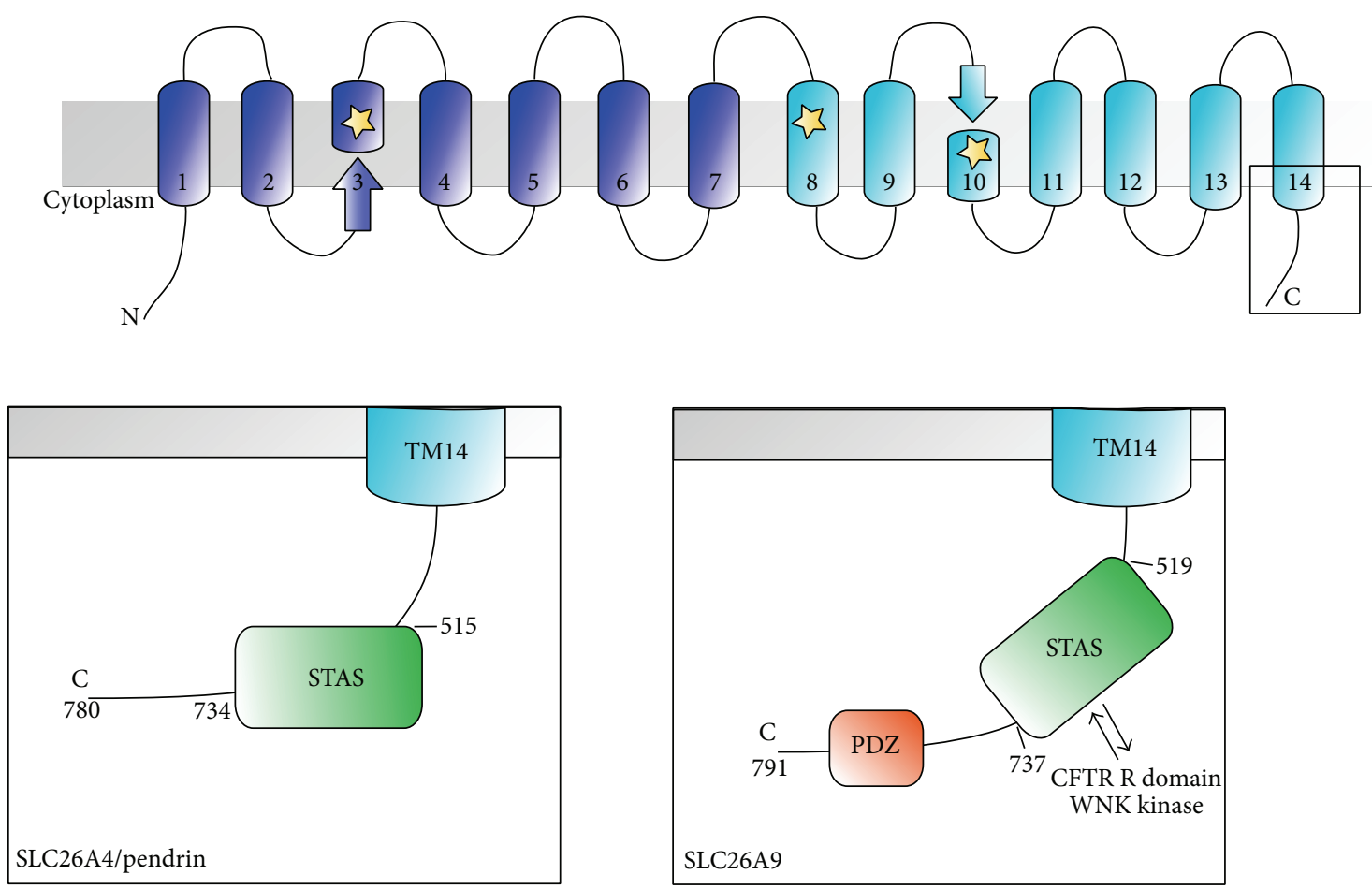

FIGURE 4: Domain architecture schematic for human SLC26 family proteins discussed here, SLC26A4 (pendrin) and SLC26A9, based on the crystal structure of SLC26Dg (PDB ID 5DA0). Upper inset shows general schematic while the lower insets show details of the C-terminal cytoplasmic region for each protein. Labels denote the following domains: STAS: sulfate transporter and antisigma factor antagonist domain; PDZ: PSD95-Dlg1-Zo-1 domain. Locations of SLC26A9 interaction with CFTR R domains and WNK kinases are denoted. The location of residues of a crystallographically determined ligand binding site is highlighted with stars.

diseases including bronchial asthma, COPD, and rhinovirus infection, rhinitis, and chronic rhinosinusitis [54, 55, 81-86].

The association between pendrin and inflammatory airway disease was first proposed in 2005, when it was observed that pendrin expression was upregulated in three different murine asthma models, including transgenic overexpression of IL-13 in lung [83]. Later, it was reported that induction of asthma or COPD in mice by inhalation of ovalbumin or elastase, respectively, resulted in increased pendrin expression; direct overexpression of pendrin in the lung led to increased mucus production and secretion and neutrophilic infiltration [86]. In subsequent works, the link between inflammatory cytokines, in particular IL- 4 and IL-13, and pendrin overexpression has been cemented $[81,85,87]$, and in a recent study SLC26A4 was identified as the most upregulated gene in human asthmatic bronchi [88]. A major downstream effect of IL-4 and IL-13 signaling is the activation of the signal transducer and activator of transcription 6 (STAT6). Following ligand-receptor binding, associated Janus kinases (JAKs) activate the receptor, allowing STAT6 to then be recruited and activated by phosphorylation. Once phosphorylated, STAT6 homodimerizes and translocates to the nucleus where it regulates the transcription of target genes via binding to $\mathrm{N} 4$ interferon $\gamma$ activated sequences $\left(\mathrm{N}_{4} \mathrm{GAS}\right)$ in the promoter region [89]. The pendrin promoter contains at least one $\mathrm{N}_{4}$ GAS motif, and STAT6 has been shown to bind this sequence in vitro, thus suggesting that increases in pendrin promoter activity via STAT6 represent at least one mechanism by which IL- 4 and IL-13 increase pendrin activity [87]. Cytokines other than IL-4 and IL-13 may be responsible for increases in pendrin expression; IL-1 $\beta$, a macrophagesecreted cytokine involved in the immunopathogenesis of asthma and COPD, has also been shown to increase pendrin levels in rodent and human bronchial epithelial cells [74, 90].

Signaling through IL-4/IL-13 mediates airway hyperresponsiveness, eosinophilic inflammation, mucus cell metaplasia and mucus overproduction, subepithelial fibrosis, and increased viscosity of the airway surface liquid (ASL), all of which are common to bronchial asthma and COPD [91]. Pendrin may play a major role in the pathogenesis of asthma or COPD by regulating some of these responses, in particular ASL thickness and mucus production (Figure 5). In lung epithelial cells, reabsorptive $\mathrm{Na}^{+}$transport through $\mathrm{ENaC}$ is suppressed whereas secretory $\mathrm{Cl}^{-}$transport through CFTR and $\mathrm{CaCCs}$ is stimulated, which collectively results in a net secretory phenotype whereby water osmotically flows into the lumen and ASL viscosity decreases. On the other hand, pendrin imports $\mathrm{Cl}^{-}$in exchange for other anions, and thus an IL-4/IL-13-mediated increase in pendrin activity may shift the equilibrium towards a reabsorptive phenotype, resulting in the osmotic flow of water into the interstitium and the thinning of the ASL [85]. In asthmatic mice, mucus overproduction is accompanied by an increased pendrin expression at the apical surface of bronchial epithelial cells, 


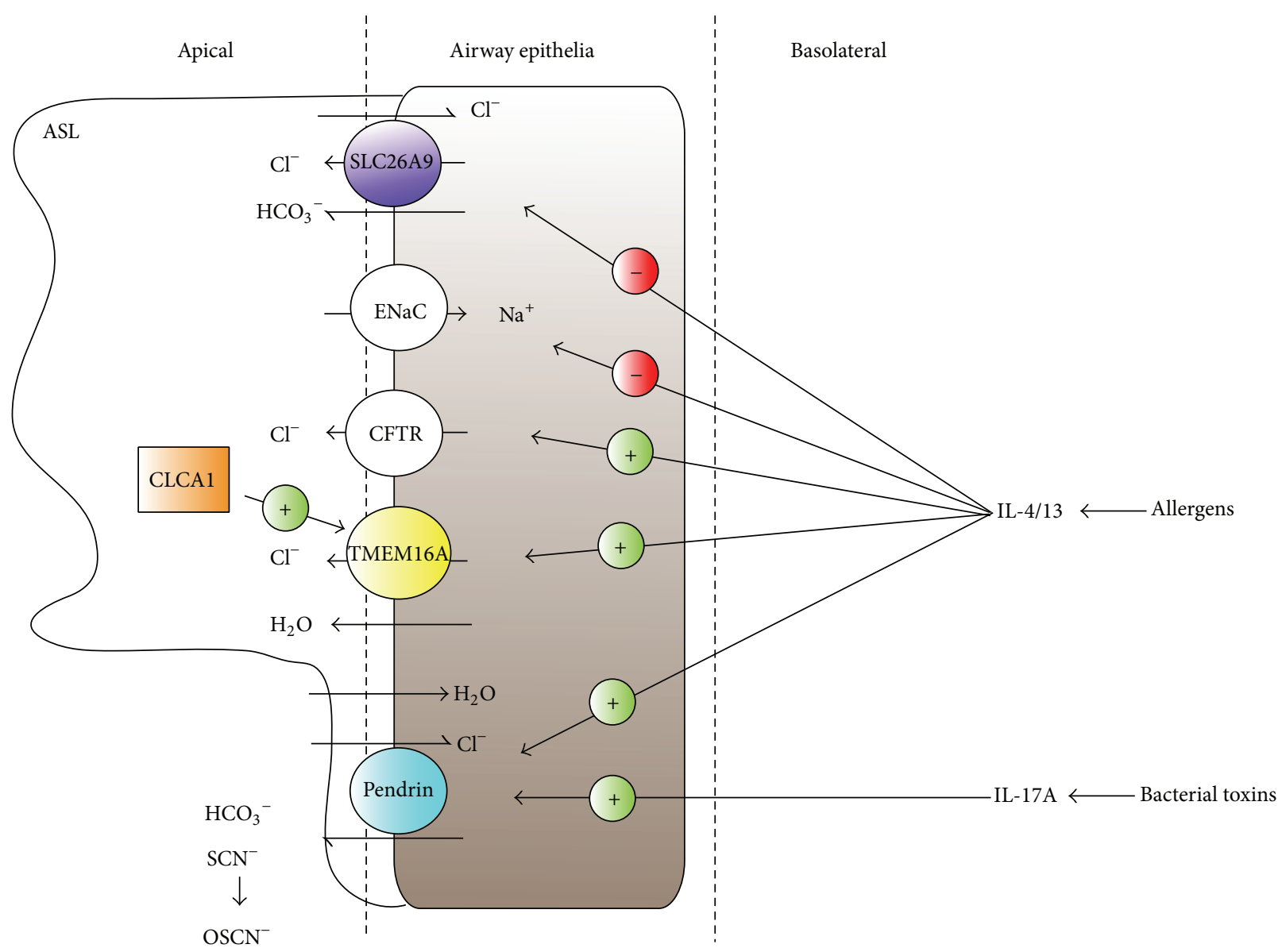

FIGURE 5: Roles of ion channels in the airway epithelium. In response to allergens and other asthma and COPD exacerbating factors, Th2cytokines IL-4 and IL-13 induce a water secretory phenotype by stimulating $\mathrm{Cl}^{-}$secretion via CFTR and $\mathrm{Ca}^{2+}$-activated $\mathrm{Cl}^{-}$channels such as TMEM16A and by decreasing $\mathrm{Na}^{+}$and $\mathrm{Cl}^{-}$reabsorption via ENaC and SLC26A9, respectively, which leads to the thickening of the airway surface liquid (ASL). TMEM16A activity can be increased by secreted CLCA1 protein. In concert, signaling through IL-4/IL-13 increases the functional expression of pendrin, which results in reabsorption of water and thinning of the ASL. Pendrin can also increase the secretion of thiocyanate $\left(\mathrm{SCN}^{-}\right)$, a substrate for the production of the antimicrobial agent hypothiocyanite $\left(\mathrm{OSCN}^{-}\right)$by the lactoperoxidase system. Toxins from $B$. pertussis and other bacteria trigger an IL-17A-mediated inflammatory host response in the lung epithelium, which is characterized by a significant upregulation of pendrin activity.

and in pendrin overexpression cell models, production of MUC5AC, a major mucus protein in asthma and COPD patients, is increased [86]. In mice, pendrin overexpression is also accompanied by neutrophil-dominant inflammation, suggesting that, in this system, mucus production may be induced not only by a direct effect of pendrin on airway epithelial cells, but also by an indirect effect of pendrin by recruiting inflammatory neutrophils [86].

In bronchial epithelial cells, IL-4/IL-13 signaling upregulates the expression of CLCA1 [9], CFTR [92], and pendrin [87], whereas it downregulates the expression of the $\beta$ and $\gamma$ subunits of ENaC. Because upregulation of certain proteins, such as pendrin, might aggravate asthma or COPD symptoms, whereas the downregulation of $\mathrm{ENaC}$ and the downregulation of CLCA1 might be protective (Figure 5), it is unsurprising that pharmacological strategies aimed at the blocking of the IL-4/IL-13 pathway are not as successful as they were anticipated to be [93]. Selective inhibition of pendrin could be an intriguing new strategy for asthma/COPD therapy, but as noted above, pendrin contributes to the secretion of $\mathrm{SCN}^{-}$, a substrate of lactoperoxidase for the production of the protective, antimicrobial OSCN ${ }^{-}$[74], and this should be taken into account when exploring novel treatment avenues.

4.3. The Next Frontier: Pendrin and Infectious Lung Disease. Most recently, pendrin has been implicated in the IL-17Adependent host inflammatory response to bacterial airway infections (Figure 5) [56, 57]. IL-17A is critical for the immune response of the lung to infectious bacteria, for example, Haemophilus influenzae, Staphylococcus aureus, Klebsiella pneumoniae, and Bordetella pertussis [94]. The latter is the etiologic agent of whooping cough, or pertussis disease, which is a resurgent condition of great clinical concern as it can progress to pulmonary inflammation and death in infants and for which there is no effective treatment [95]. Pertussis toxin (PT), the virulence factor of $B$. pertussis, undermines the host immune system by inhibiting macrophage and neutrophil 
responses, suppressing the production of antibodies against the bacteria, and inducing proinflammatory cytokines, in particular IL-17A [96]. One of the most highly upregulated genes in association with PT activity is SLC26A4 [97, 98], and pendrin is upregulated in human bronchial epithelial cells exposed to IL-17A [56]. In the lungs of B. pertussis-infected mice there is an increase in pendrin levels that is concomitant with an increase in IL-17A but not in IL-4/IL-13 levels, and pendrin upregulation is significantly hampered in $\mathrm{Il}-17 \mathrm{a}$ null mice [57]. Other host factors may be involved in PTdependent upregulation of pendrin, such as IL- $1 \beta$ and IFN- $\gamma$, as both are upregulated during $B$. pertussis infection and have been linked with pendrin upregulation [85, 98, 99]. Taken together, these recent advances suggest that the upregulation of pendrin, with its associated inflammatory pathology, is a major mechanism of virulence for the pertussis toxin and position pendrin as a potential novel therapeutic target for the treatment of whooping cough.

4.4. SLC26A9: A Novel CFTR Regulator. SLC26A9 is another member of the SLC26 family of anion exchangers and channels. It is robustly expressed in apical airway epithelia [100] and gastric parietal cells [101] and to a lesser extent in the kidney, brain, and reproductive tracts [59, 102-104]. The function of SLC26A9 is still unclear: it has been described as a $\mathrm{Cl}^{-}$channel with a small degree of bicarbonate transport [104], a $\mathrm{Cl}^{-}$channel or a $\mathrm{Cl}^{-} / \mathrm{HCO}_{3}{ }^{-}$exchanger $[105,106]$. One group reported increased $\mathrm{Cl}^{-}$conductance particularly in high bicarbonate conditions [107], and others have found that SLC26A9 activity is coupled to $\mathrm{Na}^{+}$transport $[58,103$, 108]. Like other members of the family, SLC26A9 is predicted to span the membrane 14 times, and it contains a STAS domain followed by a PSD95-Dlg1-Zo-1 (PDZ) domain in the C-terminal cytoplasmic region (Figure 4) $[59,109]$. Two groups propose that SLC26 proteins, including SLC26A9, interact with CFTR initially via their PDZ domains [110, 111]. This is followed by a stronger interaction between the CFTR R domain and the SLC26 STAS domain, which is enhanced by PKA-dependent phosphorylation of the $\mathrm{R}$ domain [111-113]. The interaction between SLC26A9 and CFTR has been described in multiple studies. However, whether the interaction is stimulatory or inhibitory is still controversial and may be cell type-dependent [108, 114]. Not much is known about the regulation of SLC26A9, but WNK kinases, also known to regulate other transporters and channels involved in osmoregulation, have been shown to inhibit SLC26A9 activity via interaction with the STAS domain [109]. Though the influence of SLC26A9 on CFTR has been reported, the reciprocal interaction is less clear. Multiple groups have described CFTR regulation of SLC26A9 activity and expression, but the results are not consistent [58, 114-118]. Evidence of CFTR and SLC26A9 coexpression has been found in the lung, trachea, stomach, and sweat gland [119].

Due to its high expression in the lung, numerous studies have investigated the role of SLC26A9 in lung disease. Anagnostopoulou and colleagues [120] first reported that SLC26A9 activity is responsible for increased constitutive $\mathrm{Cl}^{-}$current under Th2 inflammatory conditions, but not in normal physiology. The authors also found that SLC26A9 prevents airway mucous obstruction after stimulation with IL-13. These changes were due to increased SLC26A9 activity, which may be due to changes in regulation by WNK kinases [104]. Unlike CFTR and TMEM16A, SLC26A9 is downregulated in patients with allergic asthma (Figure 4). Further investigation revealed that a SNP in the $3^{\prime}$ UTR of the SLC26A9 gene likely reduced expression levels in these patients, possibly through enhanced binding of hsa-miR-632 [120].

SLC26A9 has also been implicated in the pathogenesis of bronchiectasis, the widening of airways frequently due to mucous obstruction, a condition often seen in patients with cystic fibrosis. A recent report [119] identified two patients with diffuse idiopathic bronchiectasis who also had mutations in the SLC26A9 gene. One patient presented with a mutation in a transmembrane domain of SLC26A9 (V486I); the patient's brother was asymptomatic, though he had the same mutation. The second patient presented with a mutation in the STAS domain of SLC26A9 (R575W) in addition to the Fdel508 mutation in CFTR. Coexpression of both mutants in Xenopus oocytes provided evidence of a decreased interaction between the SLC26A9 STAS domain and the R domain of CFTR. It is thought that wild-type SLC26A9, in conjunction with CFTR loss, may enhance ion conductance and fluid secretion [121]. Thus, loss of SLC26A9, in the setting of CFTR loss, may result in reduced airway surface liquid hydration, mucous blockage, and consequent bronchiectasis. The authors of the study further narrow the CFTR-SLC26A9 interaction region to a peptide within the STAS domain but do not confirm that the R575W mutation in this peptide disrupts the interaction and activation [119]. In contrast, a second group did not report changes in $\mathrm{Cl}^{-}$transport with the R575W mutation [122]. As the second patient's daughter only carried the Fdel508 mutation and was asymptomatic, the authors speculate that one mutation in CFTR is not sufficient to produce the CF phenotype [119]. However, mutations in modifier genes, such as SLC26A9, may contribute to CF in those heterozygous for CFTR mutations. Thus, SLC26A9 may influence phenotypic expression of heterozygous mutations in ion channels (CFTR, ENaC, and others) involved in airway surface liquid hydration [119].

Further supporting the modifier gene hypothesis, some SLC26A9 mutations have been shown to increase the risk of meconium ileus in patients with CF [123], as well as CFrelated diabetes onset [124] and pancreatic disease severity $[108,125]$. In the case of CFTR and SLC26A9 double mutations, the exact mechanism causing the phenotype must be further investigated as $\mathrm{Cl}^{-}$transport could be due to altered CFTR and/or SLC26A9 function or to impaired regulation of CFTR by SLC26A9 or vice versa $[119,124]$. Understanding the various mechanisms of SLC26A9 mutations will be important towards developing therapies that can improve lung diseases such as asthma, CF, and bronchiectasis.

\section{Conclusions}

Chloride transport proteins play crucial roles in airway health and disease. On one hand, they contribute to proper 
mucus function by controlling mucus hydration and $\mathrm{pH}$ via controlling chloride and bicarbonate ion transport. On the other hand, they may play a direct role in mucus synthesis, secretion, and AHR. Recent animal model studies have emphasized the crucial role that mucus and mucin proteins play in innate mucosal immunology. Deletion of MUC5B (the main secreted mucin protein produced in the airway under homeostatic conditions) results in impaired mucociliary clearance and increased microbial infection [126]. Knockout of CFTR in pig results in airway mucus that is more acidic and deficient in antimicrobial activity due to loss of defensin function at low $\mathrm{pH}[3,127]$ and is also deficient in mucociliary clearance as it remains tethered to secreting cells [128]. This could be due to improper proteolytic processing of mucin proteins, since loss of CFTR function in the intestine impairs $\beta$-meprin processing and release of secreted mucins in that setting [129]. Thus a complete understanding of how these channels contribute to mucus synthesis, secretion, function, and mucociliary clearance is required to understand the impact of modulating their activity.

\section{Conflict of Interests}

The authors declare that there is no conflict of interests regarding publication of this paper.

\section{Authors' Contribution}

Monica Sala-Rabanal and Zeynep Yurtsever contributed equally to this work.

\section{Acknowledgments}

This work was supported by NIH R01-HL119813 (to Tom J. Brett), American Heart Association Predoctoral Fellowship PRE19970008 (to Zeynep Yurtsever), and NIH T32GM07200 (to Kayla N. Berry).

\section{References}

[1] A. S. Verkman and L. J. Galietta, "Chloride channels as drug targets," Nature Reviews Drug Discovery, vol. 8, pp. 153-171, 2009.

[2] J. V. Fahy and B. F. Dickey, "Airway mucus function and dysfunction," The New England Journal of Medicine, vol. 363, no. 23, pp. 2233-2247, 2010.

[3] A. A. Pezzulo, X. X. Tang, M. J. Hoegger et al., "Reduced airway surface $\mathrm{pH}$ impairs bacterial killing in the porcine cystic fibrosis lung," Nature, vol. 487, no. 7405, pp. 109-113, 2012.

[4] W. W. Busse and R. F. Lemanske Jr., "Asthma," The New England Journal of Medicine, vol. 344, pp. 350-362, 2001.

[5] M. E. Loewen and G. W. Forsyth, "Structure and function of CLCA proteins," Physiological Reviews, vol. 85, no. 3, pp. 10611092, 2005.

[6] A. Nakanishi, S. Morita, H. Iwashita et al., "Role of gob-5 in mucus overproduction and airway hyperresponsiveness in asthma," Proceedings of the National Academy of Sciences of the United States of America, vol. 98, no. 9, pp. 5175-5180, 2001.
[7] A. C. Patel, J. D. Morton, E. Y. Kim et al., "Genetic segregation of airway disease traits despite redundancy of calcium-activated chloride channel family members," Physiological Genomics, vol. 25, no. 3, pp. 502-513, 2006.

[8] M. Hoshino, S. Morita, H. Iwashita et al., "Increased expression of the human $\mathrm{Ca}^{2+}$-activated $\mathrm{Cl}^{-}$channel $1(\mathrm{CaCC})$ gene in the asthmatic airway," American Journal of Respiratory and Critical Care Medicine, vol. 165, no. 8, pp. 1132-1136, 2002.

[9] Y. G. Alevy, A. C. Patel, A. G. Romero et al., "IL-13-induced airway mucus production is attenuated by MAPK13 inhibition," The Journal of Clinical Investigation, vol. 122, pp. 4555-4568, 2012.

[10] L. Mundhenk, B. Johannesson, P. Anagnostopoulou et al., "mCLCA3 does not contribute to calcium-activated chloride conductance in murine airways," American Journal of Respiratory Cell and Molecular Biology, vol. 47, no. 1, pp. 87-93, 2012.

[11] A. C. Patel, T. J. Brett, and M. J. Holtzman, "The role of CLCA proteins in inflammatory airway disease," Annual Review of Physiology, vol. 71, pp. 425-449, 2009.

[12] M. C. Peters, Z. K. Mekonnen, S. Yuan, N. R. Bhakta, P. G. Woodruff, and J. V. Fahy, "Measures of gene expression in sputum cells can identify $\mathrm{T}_{\mathrm{H}}$ 2-high and $\mathrm{T}_{\mathrm{H}}$ 2-low subtypes of asthma," Journal of Allergy and Clinical Immunology, vol. 133, no. 2, pp. 388.e5-394.e5, 2014.

[13] A. Gibson, A. P. Lewis, K. Affleck, A. J. Aitken, E. Meldrum, and N. Thompson, "HCLCA1 and mCLCA3 are secreted nonintegral membrane proteins and therefore are not ion channels," Journal of Biological Chemistry, vol. 280, no. 29, pp. 2720527212, 2005.

[14] S. A. Cunningham, M. S. Awayda, J. K. Bubien et al., "Cloning of an epithelial chloride channel from bovine trachea," The Journal of Biological Chemistry, vol. 270, no. 52, pp. 31016-31026, 1995.

[15] R. Gandhi, R. C. Elble, A. D. Gruber et al., "Molecular and functional characterization of a calcium-sensitive chloride channel from mouse lung," Journal of Biological Chemistry, vol. 273, no. 48, pp. 32096-32101, 1999.

[16] A. D. Gruber, R. C. Elble, H.-L. Ji, K. D. Schreur, C. M. Fuller, and B. U. Pauli, "Genomic cloning, molecular characterization, and functional analysis of human CLCA1, the first human member of the family of $\mathrm{Ca}^{2+}$-activated $\mathrm{Cl}$ - channel proteins," Genomics, vol. 54, no. 2, pp. 200-214, 1998.

[17] T. Nakano, H. Inoue, S. Fukuyama et al., "Niflumic acid suppresses interleukin-13-induced asthma phenotypes," American Journal of Respiratory and Critical Care Medicine, vol. 173, no. 11, pp. 1216-1221, 2006.

[18] Z. Yurtsever, M. Sala-Rabanal, D. T. Randolph et al., "Selfcleavage of human CLCA1 protein by a novel internal metalloprotease domain controls calcium-activated chloride channel activation," The Journal of Biological Chemistry, vol. 287, no. 50, pp. 42138-42149, 2012.

[19] M. Hamann, A. Gibson, N. Davies et al., "Human ClCal modulates anionic conduction of calcium-dependent chloride currents," Journal of Physiology, vol. 587, no. 10, pp. 2255-2274, 2009.

[20] M. Sala-Rabanal, Z. Yurtsever, C. G. Nichols, and T. J. Brett, "Secreted CLCA1 modulates TMEM16A to activate $\mathrm{Ca}^{2+}$ dependent chloride currents in human cells," eLife, vol. 4, Article ID e05875, 2015.

[21] M. K. Bothe, L. Mundhenk, M. Kaup, C. Weise, and A. D. Gruber, "The murine goblet cell protein mCLCA3 is a zinc-dependent metalloprotease with autoproteolytic activity," Molecules and Cells, vol. 32, no. 6, pp. 535-541, 2011. 
[22] A. J. Long, J. P. Sypek, R. Askew et al., "Gob-5 contributes to goblet cell hyperplasia and modulates pulmonary tissue inflammation," American Journal of Respiratory Cell and Molecular Biology, vol. 35, no. 3, pp. 357-365, 2006.

[23] K. Dietert, K. Reppe, L. Mundhenk, M. Witzenrath, and A. D. Gruber, "mCLCA3 modulates IL-17 and CXCL-1 induction and leukocyte recruitment in murine Staphylococcus aureus pneumonia," PLoS ONE, vol. 9, no. 7, Article ID e102606, 2014.

[24] J. C. H. Ching, L. Lobanova, and M. E. Loewen, "Secreted hCLCA1 is a signaling molecule that activates airway macrophages," PLoS ONE, vol. 8, no. 12, Article ID e83130, 2013.

[25] A. Caputo, E. Caci, L. Ferrera et al., “TMEM16A, a membrane protein associated with calcium-dependent chloride channel activity," Science, vol. 322, no. 5901, pp. 590-594, 2008.

[26] B. C. Schroeder, T. Cheng, Y. N. Jan, and L. Y. Jan, "Expression cloning of TMEM16A as a calcium-activated chloride channel subunit," Cell, vol. 134, no. 6, pp. 1019-1029, 2008.

[27] Y. D. Yang, H. Cho, J. Y. Koo et al., “TMEM16A confers receptoractivated calcium-dependent chloride conductance," Nature, vol. 455, no. 7217, pp. 1210-1215, 2008.

[28] R. Schreiber, I. Uliyakina, P. Kongsuphol et al., "Expression and function of epithelial anoctamins," The Journal of Biological Chemistry, vol. 285, no. 10, pp. 7838-7845, 2010.

[29] Y. Tian, R. Schreiber, and K. Kunzelmann, "Anoctamins are a family of $\mathrm{Ca}^{2+}$-activated $\mathrm{Cl}^{-}$channels," Journal of Cell Science, vol. 125, no. 21, pp. 4991-4998, 2012.

[30] F. Huang, J. R. Rock, B. D. Harfe et al., "Studies on expression and function of the TMEM16A calcium-activated chloride channel," Proceedings of the National Academy of Sciences of the United States of America, vol. 106, no. 50, pp. 21413-21418, 2009.

[31] J. D. Brunner, N. K. Lim, S. Schenck, A. Duerst, and R. Dutzler, "X-ray structure of a calcium-activated TMEM16 lipid scramblase," Nature, vol. 516, no. 7530, pp. 207-212, 2014.

[32] J. Tien, H. Y. Lee, D. L. Minor Jr., Y. N. Jan, and L. Y. Jan, "Identification of a dimerization domain in the TMEM16A calciumactivated chloride channel (CaCC)," Proceedings of the National Academy of Sciences of the United States of America, vol. 110, no. 16, pp. 6352-6357, 2013.

[33] H. Terashima, A. Picollo, and A. Accardi, "Purified TMEM16A is sufficient to form $\mathrm{Ca}^{2+}$-activated $\mathrm{Cl}^{-}$channels," Proceedings of the National Academy of Sciences of the United States of America, vol. 110, no. 48, pp. 19354-19359, 2013.

[34] C. J. Peters, H. Yu, J. Tien, Y. N. Jan, M. Li, and L. Y. Jan, “Four basic residues critical for the ion selectivity and pore blocker sensitivity of TMEM16A calcium-activated chloride channels," Proceedings of the National Academy of Sciences, vol. 112, no. 11, pp. 3547-3552, 2015.

[35] J. Tien, C. J. Peters, X. M. Wong et al., "A comprehensive search for calcium binding sites critical for TMEM16A calciumactivated chloride channel activity," eLife, 2014.

[36] J. Jung, J. H. Nam, H. W. Park, U. Oh, J.-H. Yoon, and M. G. Lee, "Dynamic modulation of ANO1/TMEM16A $\mathrm{HCO}_{3}^{-}$permeability by $\mathrm{Ca}^{2+}$ /calmodulin," Proceedings of the National Academy of Sciences of the United States of America, vol. 110, no. 1, pp. 360-365, 2013.

[37] Y. Yu, A.-S. Kuan, and T.-Y. Chen, "Calcium-calmodulin does not alter the anion permeability of the mouse TMEM16A calcium-activated chloride channel," Journal of General Physiology, vol. 144, no. 1, pp. 115-124, 2014.
[38] J. Lin, Y. Jiang, L. Li, Y. Liu, H. Tang, and D. Jiang, “TMEM16A mediates the hypersecretion of mucus induced by Interleukin13," Experimental Cell Research, vol. 334, no. 2, pp. 260-269, 2015.

[39] A. Mazzone, S. J. Gibbons, C. E. Bernard et al., "Identification and characterization of a novel promoter for the human ANO1 gene regulated by the transcription factor signal transducer and activator of transcription 6 (STAT6)," The FASEB Journal, vol. 29, no. 1, pp. 152-163, 2015.

[40] W. Namkung, P.-W. Phuan, and A. S. Verkman, “TMEM16A inhibitors reveal TMEM16A as a minor component of calciumactivated chloride channel conductance in airway and intestinal epithelial cells," Journal of Biological Chemistry, vol. 286, no. 3, pp. 2365-2374, 2011.

[41] P. Scudieri, E. Caci, S. Bruno et al., "Association of TMEM16A chloride channel overexpression with airway goblet cell metaplasia," Journal of Physiology, vol. 590, no. 23, pp. 6141-6155, 2012.

[42] F. Huang, H. Zhang, M. Wu et al., "Calcium-activated chloride channel TMEM16A modulates mucin secretion and airway smooth muscle contraction," Proceedings of the National Academy of Sciences of the United States of America, vol. 109, no. 40, pp. 16354-16359, 2012.

[43] R. J. Lee and J. K. Foskett, "Mechanisms of $\mathrm{Ca}^{2+}$-stimulated fluid secretion by porcine bronchial submucosal gland serous acinar cells," The American Journal of Physiology-Lung Cellular and Molecular Physiology, vol. 298, no. 2, pp. L210-L231, 2010.

[44] Y. Zhang, X. Wang, H. Wang et al., "TMEM16A-mediated mucin secretion in IL-13-induced nasal epithelial cells from chronic rhinosinusitis patients," Allergy, Asthma \& Immunology Research, vol. 7, no. 4, pp. 367-375, 2015.

[45] W. Namkung, Z. Yao, W. E. Finkbeiner, and A. S. Verkman, "Small-molecule activators of TMEM16A, a calcium-activated chloride channel, stimulate epithelial chloride secretion and intestinal contraction," The FASEB Journal, vol. 25, no. 11, pp. 4048-4062, 2011.

[46] I. Leverkoehne and A. D. Gruber, "The murine mCLCA3 (alias gob-5) protein is located in the mucin granule membranes of intestinal, respiratory, and uterine goblet cells," Journal of Histochemistry and Cytochemistry, vol. 50, no. 6, pp. 829-838, 2002.

[47] K. L. Raiford, J. Park, K.-W. Lin, S. Fang, A. L. Crews, and K. B. Adler, "Mucin granule-associated proteins in human bronchial epithelial cells: the airway goblet cell 'granulome"' Respiratory Research, vol. 12, article 118, 2011.

[48] L. Q. Song, Y. Li, W. N. Li, W. Zhang, H. W. Qi, and C. G. Wu, "Safety and immunogenicity of a DNA vaccine encoding human calcium-activated chloride channel 1 (hCLCA1) in asthmatic mice," International Archives of Allergy and Immunology, vol. 161, no. 3, pp. 243-251, 2013.

[49] L. Song, D. Liu, C. Wu et al., "Antibody to mCLCA3 suppresses symptoms in a mouse model of asthma," PLoS ONE, vol. 8, no. 12, Article ID e82367, 2013.

[50] D. M. Boedtkjer, S. Kim, A. B. Jensen, V. M. Matchkov, and K. E. Andersson, "New selective inhibitors of calcium-activated chloride channels-T16Ainh-A01, CaCCinh-A01 and MONNAwhat do they inhibit?" British Journal of Pharmacology, vol. 172, no. 16, pp. 4158-4172, 2015.

[51] A. Ghosh, R. C. Boucher, and R. Tarran, "Airway hydration and COPD," Cellular and Molecular Life Sciences, vol. 72, no. 19, pp. 3637-3652, 2015. 
[52] E. Sondo, E. Caci, and L. J. V. Galietta, "The TMEM16A chloride channel as an alternative therapeutic target in cystic fibrosis," International Journal of Biochemistry and Cell Biology, vol. 52, pp. 73-76, 2014.

[53] C. Nofziger, S. Dossena, S. Suzuki, K. Izuhara, and M. Paulmichl, "Pendrin function in airway epithelia," Cellular Physiology and Biochemistry, vol. 28, no. 3, pp. 571-578, 2011.

[54] S. Seshadri, X. Lu, M. R. Purkey et al., "Increased expression of the epithelial anion transporter pendrin/SLC26A4 in nasal polyps of patients with chronic rhinosinusitis," The Journal of Allergy and Clinical Immunology, 2015.

[55] A. Ishida, N. Ohta, Y. Suzuki et al., "Expression of pendrin periostin in allergic rhinitis chronic rhinosinusitis," Allergology International, vol. 61, no. 4, pp. 589-595, 2012.

[56] K. M. Adams, V. Abraham, D. Spielman et al., "IL-17A induces Pendrin expression and chloride-bicarbonate exchange in human bronchial epithelial cells," PLOS ONE, vol. 9, no. 8, Article ID e103263, 2014.

[57] K. M. Scanlon, Y. Gau, J. Zhu et al., "Epithelial anion transporter pendrin contributes to inflammatory lung pathology in mouse models of Bordetella pertussis infection," Infection and Immunity, vol. 82, no. 10, pp. 4212-4221, 2014.

[58] E. El Khouri and A. Touré, "Functional interaction of the cystic fibrosis transmembrane conductance regulator with members of the SLC26 family of anion transporters (SLC26A8 and SLC26A9): physiological and pathophysiological relevance," International Journal of Biochemistry and Cell Biology, vol. 52, pp. 58-67, 2014.

[59] S. L. Alper and A. K. Sharma, "The SLC26 gene family of anion transporters and channels," Molecular Aspects of Medicine, vol. 34, no. 2-3, pp. 494-515, 2013.

[60] D. B. Mount and M. F. Romero, "The SLC26 gene family of multifunctional anion exchangers," Pflügers Archiv, vol. 447, no. 5, pp. 710-721, 2004.

[61] D. Gorbunov, M. Sturlese, F. Nies et al., "Molecular architecture and the structural basis for anion interaction in prestin and SLC26 transporters," Nature Communications, vol. 5, article $3622,2014$.

[62] E. Ohana, D. Yang, N. Shcheynikov, and S. Muallem, "Diverse transport modes by the solute carrier 26 family of anion transporters," The Journal of Physiology, vol. 587, no. 10, pp. 2179-2185, 2009.

[63] E. R. Geertsma, Y. Chang, F. R. Shaik et al., "Structure of a prokaryotic fumarate transporter reveals the architecture of the SLC26 family," Nature Structural \& Molecular Biology, vol. 22, no. 10, pp. 803-808, 2015.

[64] R. Hallworth and M. G. Nichols, "Prestin in HEK cells is an obligate tetramer," Journal of Neurophysiology, vol. 107, no. 1, pp. 5-11, 2012.

[65] L. Aravind and E. V. Koonin, "The STAS domain-a link between anion transporters and antisigma-factor antagonists," Current Biology, vol. 10, no. 2, pp. R53-R54, 2000.

[66] B. Y. Choi, H.-M. Kim, T. Ito et al., "Mouse model of enlarged vestibular aqueducts defines temporal requirement of Slc26a4 expression for hearing acquisition," The Journal of Clinical Investigation, vol. 121, no. 11, pp. 4516-4525, 2011.

[67] J.-M. Bidart, C. Mian, V. Lazar et al., "Expression of pendrin and the Pendred syndrome (PDS) gene in human thyroid tissues," Journal of Clinical Endocrinology and Metabolism, vol. 85, no. 5, pp. 2028-2033, 2000.
[68] I. E. Royaux, K. Suzuki, A. Mori et al., "Pendrin, the protein encoded by the pendred syndrome gene (PDS), is an apical porter of iodide in the thyroid and is regulated by thyroglobulin in FRTL-5 cells," Endocrinology, vol. 141, no. 2, pp. 839-845, 2000.

[69] I. E. Royaux, S. M. Wall, L. P. Karniski et al., "Pendrin, encoded by the pendred syndrome gene, resides in the apical region of renal intercalated cells and mediates bicarbonate secretion," Proceedings of the National Academy of Sciences of the United States of America, vol. 98, no. 7, pp. 4221-4226, 2001.

[70] N. Shcheynikov, D. Yang, Y. Wang et al., "The Slc26a4 transporter functions as an electroneutral $\mathrm{Cl}^{-} / \mathrm{I}^{-} / \mathrm{HCO}_{3}^{-}$exchanger: role of Slc26a4 and Slc26a6 in $\mathrm{I}^{-}$and $\mathrm{HCO}_{3}^{-}$secretion and in regulation of CFTR in the parotid duct," Journal of Physiology, vol. 586, no. 16, pp. 3813-3824, 2008.

[71] P. Wangemann, "Mouse models for pendrin-associated loss of cochlear and vestibular function," Cellular Physiology and Biochemistry, vol. 32, no. 7, pp. 157-165, 2013.

[72] P. Fong, “Thyroid iodide efflux: a team effort?" Journal of Physiology, vol. 589, no. 24, pp. 5929-5939, 2011.

[73] J. Rozenfeld, O. Tal, O. Kladnitsky et al., "Pendrin, a novel transcriptional target of the uroguanylin system," Cellular Physiology and Biochemistry, vol. 32, no. 7, pp. 221-237, 2013.

[74] N. Pedemonte, E. Caci, E. Sondo et al., "Thiocyanate transport in resting and IL-4-stimulated human bronchial epithelial cells: role of pendrin and anion channels," The Journal of Immunology, vol. 178, no. 8, pp. 5144-5153, 2007.

[75] A. J. Ratner and A. Prince, "Lactoperoxidase: new recognition of an "old" enzyme in airway defenses," American Journal of Respiratory Cell and Molecular Biology, vol. 22, no. 6, pp. 642644, 2000.

[76] B. Coyle, R. Coffey, J. A. L. Armour et al., "Pendred syndrome (goitre and sensorineural hearing loss) maps to chromosome 7 in the region containing the nonsyndromic deafness gene DFNB4," Nature Genetics, vol. 12, no. 4, pp. 421-423, 1996.

[77] P. Kopp and A. Bizhanova, "Clinical and molecular characteristics of Pendred syndrome," Annales d'Endocrinologie, vol. 72, no. 2, pp. 88-94, 2011.

[78] V. C. Sheffield, Z. Kraiem, J. C. Beck et al., "Pendred syndrome maps to chromosome 7q21-34 and is caused by an intrinsic defect in thyroid iodine organification," Nature Genetics, vol. 12, no. 4, pp. 424-426, 1996.

[79] X. C. Li, L. A. Everett, A. K. Lalwani et al., "A mutation in PDS causes non-syndromic recessive deafness," Nature Genetics, vol. 18 , no. 3, pp. 215-217, 1998.

[80] A. Bizhanova and P. Kopp, "Genetics and phenomics of Pendred syndrome," Molecular and Cellular Endocrinology, vol. 322, no. 1-2, pp. 83-90, 2010.

[81] E. Di Valentin, C. Crahay, N. Garbacki et al., "New asthma biomarkers: lessons from murine models of acute and chronic asthma," The American Journal of Physiology: Lung Cellular and Molecular Physiology, vol. 296, no. 2, pp. L185-L197, 2009.

[82] K. Izuhara, S. Ohta, H. Shiraishi et al., "The mechanism of mucus production in bronchial asthma," Current Medicinal Chemistry, vol. 16, no. 22, pp. 2867-2875, 2009.

[83] D. A. Kuperman, C. C. Lewis, and P. G. Woodruff, "Dissecting asthma using focused transgenic modeling and functional genomics," The Journal of Allergy and Clinical Immunology, vol. 116, no. 2, pp. 305-311, 2005. 
[84] C. C. Lewis, J. Y. Yang, X. Huang et al., "Disease-specific gene expression profiling in multiple models of lung disease," American Journal of Respiratory and Critical Care Medicine, vol. 177, no. 4, pp. 376-387, 2008.

[85] Y. Nakagami, S. Favoreto Jr., G. Zhen et al., "The epithelial anion transporter pendrin is induced by allergy and rhinovirus infection, regulates airway surface liquid, and increases airway reactivity and inflammation in an asthma model," Journal of Immunology, vol. 181, no. 3, pp. 2203-2210, 2008.

[86] I. Nakao, S. Kanaji, S. Ohta et al., "Identification of pendrin as a common mediator for mucus production in bronchial asthma and chronic obstructive pulmonary disease," Journal of Immunology, vol. 180, no. 9, pp. 6262-6269, 2008.

[87] C. Nofziger, V. Vezzoli, S. Dossena et al., "STAT6 links IL4/IL-13 stimulation with pendrin expression in asthma and chronic obstructive pulmonary disease," Clinical Pharmacology and Therapeutics, vol. 90, no. 3, pp. 399-405, 2011.

[88] C. Y. Yick, A. H. Zwinderman, P. W. Kunst et al., “Transcriptome sequencing (RNA-Seq) of human endobronchial biopsies: asthma versus controls," European Respiratory Journal, vol. 42, no. 3, pp. 662-670, 2013.

[89] N. C. Reich, "STATs get their move on," JAK-STAT, vol. 2, no. 4, Article ID e27080, 2013.

[90] U. Lappalainen, J. A. Whitsett, S. E. Wert, J. W. Tichelaar, and K. Bry, "Interleukin- $1 \beta$ causes pulmonary inflammation, emphysema, and airway remodeling in the adult murine lung," American Journal of Respiratory Cell and Molecular Biology, vol. 32, no. 4, pp. 311-318, 2005.

[91] D. F. Roger, "Physiology of airway mucus secretion and pathophysiology of hypersecretion," Respiratory Care, vol. 52, no. 9, pp. 1134-1146, 2007.

[92] L. J. V. Galietta, P. Pagesy, C. Folli et al., "IL-4 is a potent modulator of ion transport in the human bronchial epithelium in vitro," Journal of Immunology, vol. 168, no. 2, pp. 839-845, 2002.

[93] S. T. Holgate, "A look at the pathogenesis of asthma: the need for a change in direction," Discovery Medicine, vol. 9, no. 48, pp. 439-447, 2010.

[94] J. P. McAleer and J. K. Kolls, "Directing traffic: IL-17 and IL-22 coordinate pulmonary immune defense," Immunological Reviews, vol. 260, no. 1, pp. 129-144, 2014.

[95] J. T. Berger, J. A. Carcillo, T. P. Shanley et al., "Critical pertussis illness in children: a multicenter prospective cohort study," Pediatric Critical Care Medicine, vol. 14, no. 4, pp. 356-365, 2013.

[96] C. Andreasen, D. A. Powell, and N. H. Carbonetti, "Pertussis toxin stimulates IL-17 production in response to Bordetella pertussis infection in mice," PLoS ONE, vol. 4, no. 9, Article ID e7079, 2009.

[97] S. Banus, J. Pennings, R. Vandebriel et al., "Lung response to Bordetella pertussis infection in mice identified by geneexpression profiling," Immunogenetics, vol. 59, no. 7, pp. 555564, 2007.

[98] C. E. Connelly, Y. Sun, and N. H. Carbonetti, "Pertussis toxin exacerbates and prolongs airway inflammatory responses during Bordetella pertussis infection," Infection and Immunity, vol. 80, no. 12, pp. 4317-4332, 2012.

[99] A. Hogmalm, M. Bry, B. Strandvik, and K. Bry, "IL-1 $\beta$ expression in the distal lung epithelium disrupts lung morphogenesis and epithelial cell differentiation in fetal mice," American Journal of Physiology: Lung Cellular and Molecular Physiology, vol. 306, no. 1, pp. L23-L34, 2014.
[100] H. Lohi, M. Kujala, S. Mäkelä et al., "Functional characterization of three novel tissue-specific anion exchangers SLC26A7, -A8, and -A9," The Journal of Biological Chemistry, vol. 277, no. 16, pp. 14246-14254, 2002.

[101] J. Xu, P. Song, M. L. Miller et al., "Deletion of the chloride transporter Slc26a9 causes loss of tubulovesicles in parietal cells and impairs acid secretion in the stomach," Proceedings of the National Academy of Sciences of the United States of America, vol. 105, no. 46, pp. 17955-17960, 2008.

[102] H. Amlal, J. Xu, S. Barone, K. Zahedi, and M. Soleimani, "The chloride channel/transporter Slc26a9 regulates the systemic arterial pressure and renal chloride excretion," Journal of Molecular Medicine, vol. 91, no. 5, pp. 561-572, 2013.

[103] M. H. Chang, C. Plata, K. Zandi-Nejad et al., "Slc26a9-anion exchanger, channel and $\mathrm{Na}^{+}$transporter," Journal of Membrane Biology, vol. 228, no. 3, pp. 125-140, 2009.

[104] M. R. Dorwart, N. Shcheynikov, Y. Wang, S. Stippec, and S. Muallem, "SLC26A9 is a $\mathrm{Cl}^{-}$channel regulated by the WNK kinases," The Journal of Physiology, vol. 584, no. 1, pp. 333-345, 2007.

[105] E. S. Demitrack, M. Soleimani, and M. H. Montrose, "Damage to the gastric epithelium activates cellular bicarbonate secretion via SLC26 $9 \mathrm{Cl}^{-} / \mathrm{HCO}_{3}^{-}$exchange," American Journal of Physiology: Gastrointestinal and Liver Physiology, vol. 299, no. 1, pp. G255-G264, 2010.

[106] J. Xu, J. Henriksnäs, S. Barone et al., "SLC26A9 is expressed in gastric surface epithelial cells, mediates $\mathrm{Cl}^{-} / \mathrm{HCO}_{3}^{-}$exchange, and is inhibited by $\mathrm{NH}_{4}^{+}$," American Journal of Physiology-Cell Physiology, vol. 289, no. 2, pp. C493-C505, 2005.

[107] C. Loriol, S. Dulong, M. Avella et al., "Characterization of SLC26A9, facilitation of $\mathrm{Cl}^{-}$transport by bicarbonate," Cellular Physiology and Biochemistry, vol. 22, no. 1-4, pp. 15-30, 2008.

[108] X. Liu, T. Li, B. Riederer et al., "Loss of Slc26a9 anion transporter alters intestinal electrolyte and $\mathrm{HCO}_{3}^{-}$transport and reduces survival in CFTR-deficient mice," Pflügers Archiv-European Journal of Physiology, vol. 467, no. 6, pp. 1261-1275, 2015.

[109] M. A. Mall and L. J. Galietta, "Targeting ion channels in cystic fibrosis," Journal of Cystic Fibrosis, vol. 14, no. 5, pp. 561-570, 2015.

[110] M. N. Chernova, L. Jiang, B. E. Shmukler et al., "Acute regulation of the SLC26A3 congenital chloride diarrhoea anion exchanger (DRA) expressed in Xenopus oocytes," The Journal of Physiology, vol. 549, no. 1, pp. 3-19, 2003.

[111] S. B. Ko, W. Zeng, M. R. Dorwart et al., "Gating of CFTR by the STAS domain of SLC26 transporters," Nature Cell Biology, vol. 6, no. 4, pp. 343-350, 2004.

[112] S. B. H. Ko, N. Shcheynikov, J. Y. Choi et al., "A molecular mechanism for aberrant CFTR-dependent $\mathrm{HCO}_{3}^{-}$transport in cystic fibrosis," The EMBO Journal, vol. 21, no. 21, pp. 5662-5672, 2002.

[113] N. Shcheynikov, S. B. H. Ko, W. Zeng et al., "Regulatory interaction between CFTR and the SLC26 transporters," Novartis Foundation Symposium, vol. 273, pp. 177-186, 2006.

[114] J. Ousingsawat, R. Schreiber, and K. Kunzelmann, "Differential contribution of SLC26A9 to $\mathrm{Cl}^{-}$conductance in polarized and non-polarized epithelial cells," Journal of Cellular Physiology, vol. 227, no. 6, pp. 2323-2329, 2012.

[115] M. Avella, C. Loriol, K. Boulukos, F. Borgese, and J. Ehrenfeld, "SLC26A9 stimulates CFTR expression and function in human bronchial cell lines," Journal of Cellular Physiology, vol. 226, no. 1, pp. 212-223, 2011. 
[116] C. A. Bertrand, R. Zhang, J. M. Pilewski, and R. A. Frizzell, "SLC26A9 is a constitutively active, CFTR-regulated anion conductance in human bronchial epithelia," Journal of General Physiology, vol. 133, no. 4, pp. 421-438, 2009.

[117] J. Braun, L. Mundhenk, F. Range, and A. D. Gruber, "Quantitative expression analyses of candidates for alternative anion conductance in cystic fibrosis mouse models," Journal of Cystic Fibrosis, vol. 9, no. 5, pp. 351-364, 2010.

[118] M.-H. Chang, C. Plata, A. Sindic et al., "Slc26a9 is inhibited by the R-region of the cystic fibrosis transmembrane conductance regulator via the STAS domain," The Journal of Biological Chemistry, vol. 284, no. 41, pp. 28306-28318, 2009.

[119] N. Bakouh, T. Bienvenu, A. Thomas et al., "Characterization of SLC26A9 in patients with CF-like lung disease," Human Mutation, vol. 34, no. 10, pp. 1404-1414, 2013.

[120] P. Anagnostopoulou, B. Riederer, J. Duerr et al., "SLC26A9mediated chloride secretion prevents mucus obstruction in airway inflammation," Journal of Clinical Investigation, vol. 122, no. 10, pp. 3629-3634, 2012.

[121] M. R. Miller, D. Soave, W. Li et al., "Variants in solute carrier SLC26A9 modify prenatal exocrine pancreatic damage in cystic fibrosis," Journal of Pediatrics, vol. 166, no. 5, pp. 1152-1157.e6, 2015.

[122] A.-P. Chen, M.-H. Chang, and M. F. Romero, "Functional analysis of nonsynonymous single nucleotide polymorphisms in human SLC26A9," Human Mutation, vol. 33, no. 8, pp. 12751284, 2012.

[123] L. Sun, J. M. Rommens, H. Corvol et al., "Multiple apical plasma membrane constituents are associated with susceptibility to meconium ileus in individuals with cystic fibrosis," Nature Genetics, vol. 44, no. 5, pp. 562-569, 2012.

[124] S. M. Blackman, C. W. Commander, C. Watson et al., "Genetic modifiers of cystic fibrosis-related diabetes," Diabetes, vol. 62, no. 10, pp. 3627-3635, 2013.

[125] W. Li, D. Soave, M. R. Miller et al., "Unraveling the complex genetic model for cystic fibrosis: pleiotropic effects of modifier genes on early cystic fibrosis-related morbidities," Human Genetics, vol. 133, no. 2, pp. 151-161, 2014.

[126] M. G. Roy, A. Livraghi-Butrico, A. A. Fletcher et al., "Muc5b is required for airway defence," Nature, vol. 505, no. 7483, pp. 412416, 2014.

[127] M. H. Abou Alaiwa, L. R. Reznikov, N. D. Gansemer et al., " $\mathrm{pH}$ modulates the activity and synergism of the airway surface liquid antimicrobials beta-defensin-3 and LL-37," Proceedings of the National Academy of Sciences, vol. 111, no. 52, pp. 1870318708, 2014.

[128] M. J. Hoegger, A. J. Fischer, J. D. McMenimen et al., "Impaired mucus detachment disrupts mucociliary transport in a piglet model of cystic fibrosis," Science, vol. 345, no. 6198, pp. 818-822, 2014.

[129] A. Schütte, A. Ermund, C. Becker-Pauly et al., "Microbialinduced meprin $\beta$ cleavage in MUC2 mucin and a functional CFTR channel are required to release anchored small intestinal mucus," Proceedings of the National Academy of Sciences of the United States of America, vol. 111, no. 34, pp. 12396-12401, 2014. 


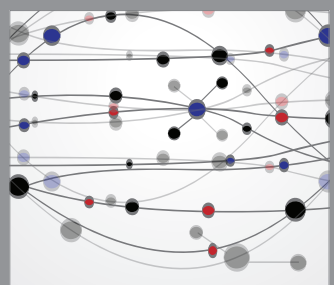

The Scientific World Journal
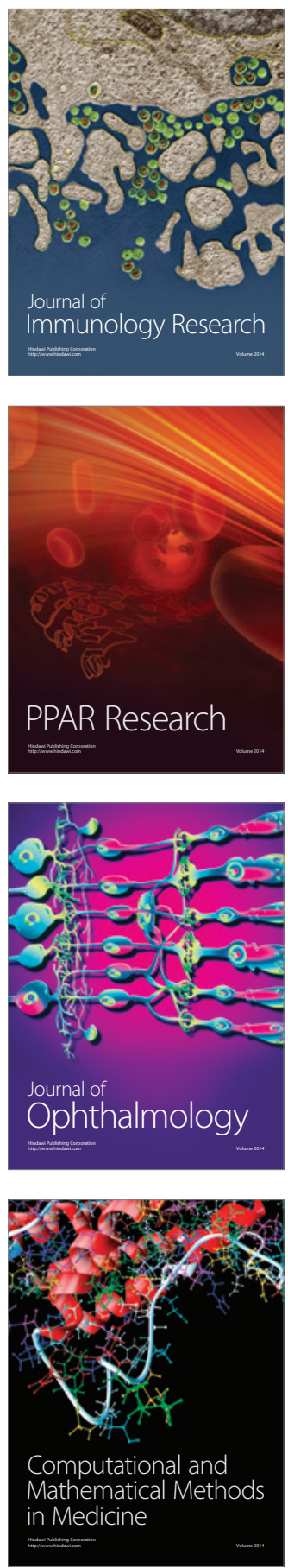

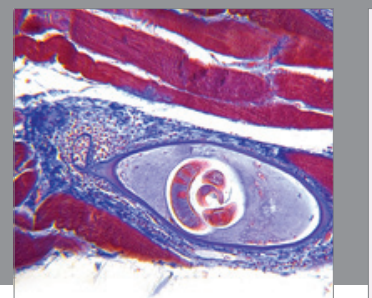

Gastroenterology

Research and Practice
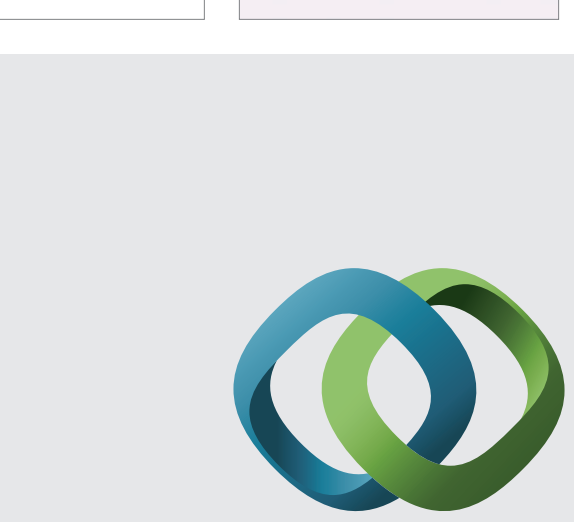

\section{Hindawi}

Submit your manuscripts at

http://www.hindawi.com
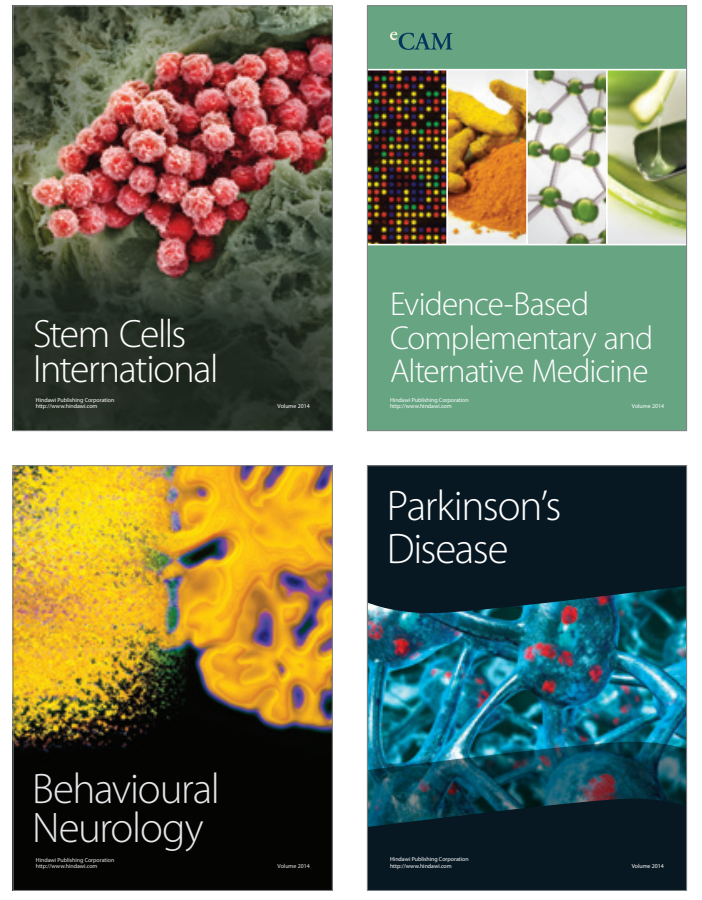
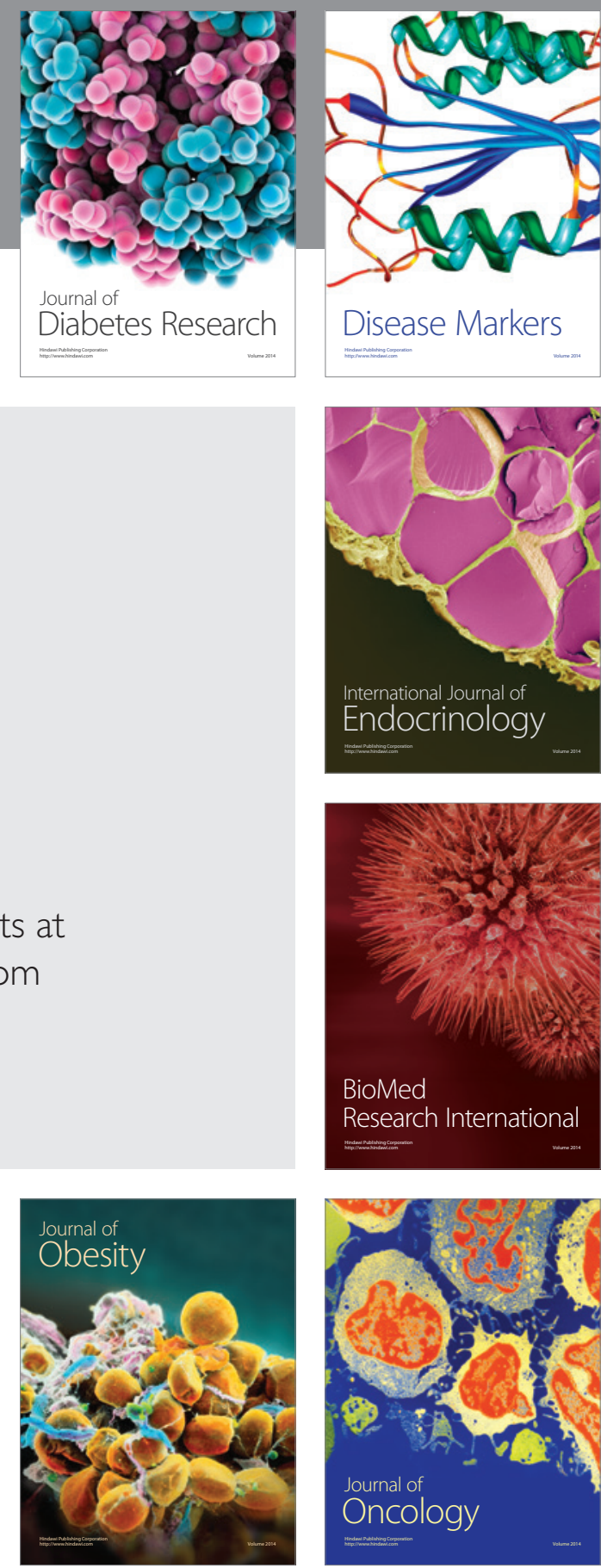

Disease Markers
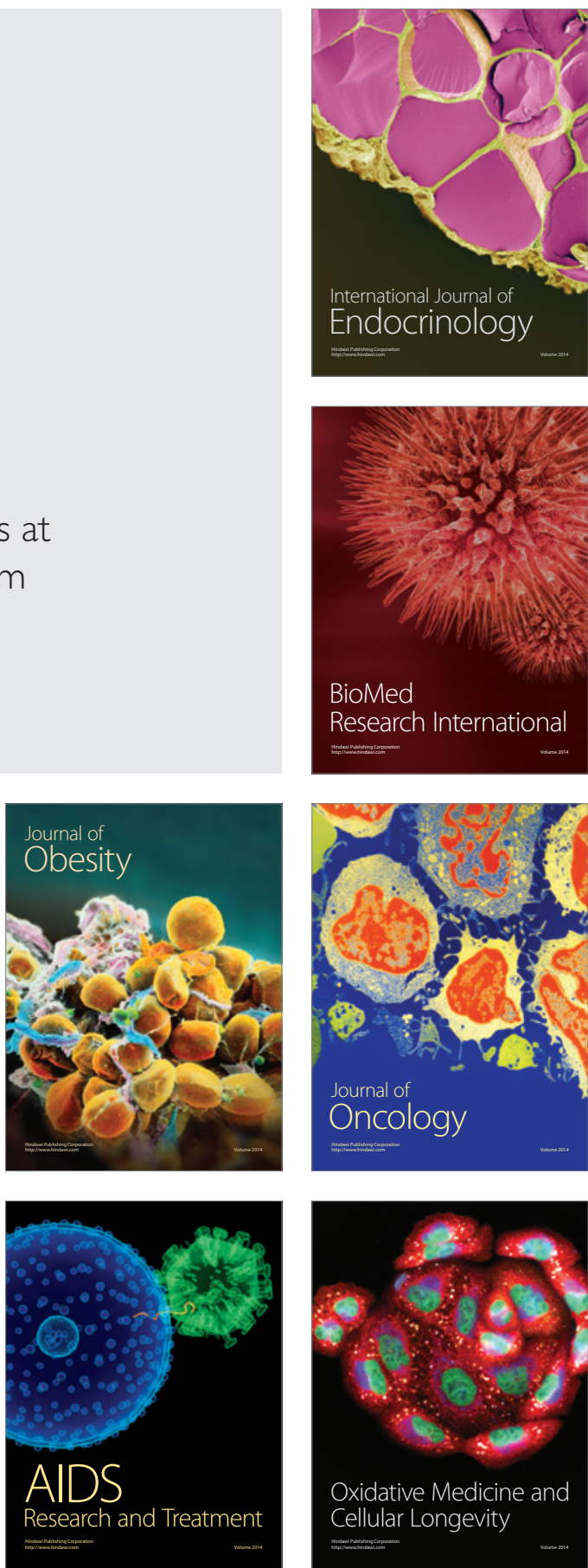